\title{
The Use of Novel and Unique Biofield Energy Healing Treatment for the Improvement of Poorly Bioavailable Compound, Berberine in Male Sprague Dawley Rats
}

\author{
Alice Branton $^{1}$, Snehasis Jana ${ }^{2, *}$ \\ ${ }^{1}$ Trivedi Global, Inc., Henderson, Nevada, USA \\ ${ }^{2}$ Trivedi Science Research Laboratory Pvt. Ltd., Bhopal, Madhya Pradesh, India
}

Email address:

publication@trivedieffect.com (S. Jana)

*Corresponding author

\section{To cite this article:}

Alice Branton, Snehasis Jana. The Use of Novel and Unique Biofield Energy Healing Treatment for the Improvement of Poorly Bioavailable Compound, Berberine in Male Sprague Dawley Rats. American Journal of Clinical and Experimental Medicine.

Vol. 5, No. 4, 2017, pp. 138-144. doi: 10.11648/j.ajcem.20170504.16

Received: May 20, 2017; Accepted: June 1, 2017; Published: July 14, 2017

\begin{abstract}
Berberine, an isoquinoline alkaloid based herbal medicine, is widely used as nutraceutical supplement for the prevention and treatment of various diseases viz. hypolipidemic, hypoglycemic, antiarrhythmic, antineoplastic, etc. The intestinal absorption and oral bioavailability of berberine is very low and almost negligible in humans. In this study, the relative oral bioavailability of berberine was studied, and the effects of The Trivedi Effect ${ }^{\mathrm{B}}$-Energy of Consciousness Healing Treatment on animals and berberine were investigated through the measurement of plasma concentrations after oral administration in rats. The test item, berberine chloride was divided into two parts. One part was denoted as the control without any Biofield Energy Healing Treatment, while the other part was defined as the Biofield Energy Treated sample, which received the Biofield Energy Healing Treatment by renowned Biofield Energy Healer, Alice Branton. Additionally, one group of animals also received Consciousness Energy Healing Treatment per se by Alice under similar conditions. Berberine oral formulations were made and administrated by oral gavage at a dose of $150 \mathrm{mg}$ per $\mathrm{kg}$ in groups viz. G1 (untreated berberine), G2 (Biofield Treated berberine) and G3 (Biofield Treated animals were received untreated berberine) group. The results showed that berberine had a very low oral plasma exposure of $179.92 \mathrm{ng} / \mathrm{mL}$ in the control group. The Biofield Energy Healing Treatment significantly enhanced the relative oral exposure $\left(\mathrm{AUC}_{0-\mathrm{t}}\right)$ of berberine by $233.40 \%$ and $35.62 \%$ in $\mathrm{G} 2$ and $\mathrm{G} 3$ groups, respectively compared to the control group. The Biofield Energy Treatment also improved plasma peak concentration $\left(\mathrm{C}_{\max }\right)$ of berberine by 37.7 and 1.4 times, in G2 and G3 groups, respectively compared to the control group. The absorption rate constant $\left(\mathrm{K}_{\mathrm{a}}\right)$ of berberine in Biofield Energy Treatment group significantly increased by $100 \%(p<0.05)$ in G2 group as compared to the control group (G1). The apparent oral plasma clearance of berberine decreased significantly $(p<0.01)$ by $81 \%$, and $50 \%$ in G2 group and G3 group, respectively as compared to the control group. The enhanced bioavailability of berberine might be due to the alteration its physicochemical properties and thermal properties by Biofield Energy Treatment. Biofield Energy Healing Treatment is considered as an innovative strategy which opens new avenues to overcome poorly absorbed drug/nutraceuticals/herbal extracts and can also improve the therapeutic performance of orally active molecules. Thereby, the Biofield Energy Treated berberine chloride having improved bioavailability can significantly increase in antibacterial, anticancer, antidiabetic, anti-obesity, anti-ischemia, memory and cognition, inhibition of metabolic syndrome and neurodegenerative diseases.
\end{abstract}

Keywords: Absorption Enhancer, Berberine Chloride, Bioavailability, P-glycoprotein, Biofield Energy Healing Treatment, Relative Oral Exposure 


\section{Introduction}

Berberine, a natural isoquinoline alkaloid obtained from various medicinal herbs such as Coptis chinensis and Hydrastis Canadensis [1]. In traditional Indian and Chinese medicine, berberine has been used for centuries for many modern applications [2]. It has been mainly used to treat diarrhea, gastroenteritis, and as abroad antibacterial/antifungal compound, which could inhibit various kind of pathogenic microbes. [3-4]. Recent research has shown that berberine has many other biological activities, such as hypolipidemic, hypoglycemic, antiarrhythmic, antiproliferative, and antineoplastic activities [5-6]. The blood lipid-reducing mechanism of berberine differs from that of statins, which suggest its significant action as hypolipidemic agent. Berberine has recently gained great interest because of its variety of bioactivities, low toxicity, and low cost properties. Given its relatively safe nature and its numerous pharmacological actions, berberine has a beneficial role in the treatment of human diseases [7-8]. Literature search data showed that there are 17 clinical trials on the efficacy of berberine for a wide range of diseases including hyperlipemia, polycystic ovary syndrome, nonalcoholic fatty liver, type-2 diabetes mellitus, prediabetes, obesity, and coronary artery disease $[3,9,10]$. There are seven completed clinical trials on the clinical efficacy of berberine, mainly related to the metabolic syndrome. Although berberine has an enormous therapeutic potential as a drug molecule, but it's poor bioavailability make an obstacle for the development as a clinical candidate. Berberine bioavailability is usually less than $1 \%$, due to its rapid biotransformation also accounts for the low plasma concentrations [11]. The $\mathrm{C}_{\max }$ of berberine in human plasma was found to be $0.4 \mathrm{ng} / \mathrm{mL}$ after a single oral dose of $400 \mathrm{mg}$ [12]. In another study, $\mathrm{C}_{\max }$ of berberine was $4 \mathrm{ng} / \mathrm{mL}$ after oral administration of $100 \mathrm{mg} / \mathrm{kg}$ in rats [13]. However, the wide application of berberine is restricted greatly due to its poor intestinal absorption and oral bioavailability. It has been reported that berberine is a substrate compound of $\mathrm{P}$ glycoprotein (P-gp), and the action of P-gp plays an important role in the absorption of berberine [14-15]. The low oral bioavailability of berberine is primarily due to its properties of low solubility and poor membrane permeability.

The Biofield Energy Healing, is a cumulative measurable electromagnetic field around the human body [16]. Use of energy medicine and healing has been studied and reported with the significant conclusions [17]. Biofield is generated from internal human processes like blood flow, lymph flow, brain functions, and heart function. Human has the ability to harness the energy from environment or Universe and can transmit into any living or nonliving object(s). Biofield energy science and healing practice has been discovered as the frontier in medicine and is accepted worldwide as alternative integrative approaches in order to promote wellness by uncovering the root cause of diseases with universal solutions. Biofield Healing has been accepted world-wide with significant clinical outcomes, which has been mentioned by National Center for Complementary and Alternative Medicine (NCCAM) as one form of complementary medicine domain. When the objects always receive the energy and responds in a useful way, that is called Biofield Energy and the process is known as Biofield Energy Treatment. The Trivedi Effect ${ }^{\mathbb{B}}$ has been reported with the significant breakthrough in living organisms and nonliving materials. Biofield Energy Healing has been reported with significant altered antimicrobial sensitivity pattern against various pathogenic microbes [18-21]. In addition, The Trivedi Effect ${ }^{\mathbb{B}}$ has also well scientifically studied in diverse areas such as materials science [22-25], biotechnology [26, 27], agriculture [28-30] and many more.

Recently, it has been reported in the literature that The Trivedi Effect $^{\circledR}$ has the significant capability to alter the physicochemical and thermal properties of various pharmaceuticals, nutraceuticals, and organic compounds through possible intervention of neutrinos [31-33]. The Trivedi Effect ${ }^{\circledR}$-Consciousness Energy Healing Treatment would be a useful approach for the enhancement of the bioavailability of pharmaceuticals and nutraceuticals. Thus, the present work was designed to evaluate The Trivedi Effect ${ }^{\mathbb{B}}$-Consciousness Energy Healing Treatment on test item (berberine), and test system (rat) through the estimation of berberine in plasma concentration after a single dose of oral administration of the test item, berberine chloride in rat.

\section{Materials and Methods}

\subsection{Chemicals and Reagents}

Berberine chloride and telmisartan were purchased from TCI, Japan and Sigma (St. Louis, MO, USA), respectively. The reagents used for sample preparation and bioanalysis included acetonitrile (HPLC Grade, Merck), methanol (HPLC Grade, Merck), water (Milli-Q), and formic acid (LCMS Grade, Fluka). USP grade nitrogen was used as the curtain gas and collision gas for LC-MS/MS were supplied from air compressor (Anesta Iwata, Japan), polypropylene tubes (Tarsons, India), class-A, measuring cylinders and volumetric flasks (Borosil, Germany) and membrane filters, $0.22 \mu \mathrm{m}$ and $0.45 \mu \mathrm{m}$ (Millipore) were used during the study. All other reagents and solvents were of analytical grade available from India.

\subsection{Energy of Consciousness Treatment Strategies}

The test item was divided into two parts. One part was considered as the control formulation and the other part was defined as the Biofield Energy Treated test item. The treated test item was subjected to The Trivedi Effect ${ }^{\mathbb{B}}$ - Energy of Consciousness Healing by Biofield Energy Healer (also known as The Trivedi Effect ${ }^{\mathbb{B}}$ ). The Biofield Energy Treatment was provided by a renowned Biofield Energy Healer, Alice Branton, USA. Additionally, one group of animals also received the Biofield Energy Treatment per se 
by the same Biofield Energy Healer under similar conditions. This Biofield Energy Treatment was provided for 3 minutes through the Biofield Energy Healer's unique Energy Transmission process (The Trivedi Effect ${ }^{\circledR}$ ), administered to the test item. Similarly, the control sample was subjected to "sham" healer for 3 minutes, under the same laboratory conditions. The sham healer did not have any knowledge about the Biofield Energy Treatment. After that, the Biofield Energy Treated and untreated test items were kept in similar sealed conditions and used for the study as per design.

\subsection{In Vivo Pharmacokinetics Study}

\subsubsection{Animals}

Male Sprague-Dawley (SD) rats (body weight 230 to 270 gm) were procured from Liveon Biosciences, Bangalore, India. Animals were housed in polycarbonate cage. Temperature and humidity were maintained at $22 \pm 3^{\circ} \mathrm{C}$ and $40-70 \%$, respectively and illumination was controlled to give a sequence of 12 hours light and 12 hours dark cycle. The temperature and humidity were recorded by auto-controlled data logger system. All the animals were provided laboratory rodent diet (Vetcare India Pvt. Ltd, Bengaluru). Reverse osmosis water treated with ultraviolet light was provided ad libitum. The experiments using animals in this investigation were performed in accordance with the guidelines provided by the Committee for the Purpose of Control and Supervision of Experiments on Animals (CPCSEA) as published in The Gazette of India, January 7, 2010 and protocol approved by the Institutional (GVK Bio) Animal Ethics Committee (IAEC approval number: BA-011).

\subsubsection{Experimental Design}

Rats were divided into three groups $(\mathrm{n}=3)$ : group 1 (Gr. 1) - per oral (p.o.) dosing of untreated berberine chloride, group 2 (Gr. 3) p. o. dosing of Biofield Energy Treated berberine chloride and group 3 (Gr. 3) p. o. dosing of untreated berberine chloride in Biofield Energy Treated animals. All animals were received per oral dose at 150 $\mathrm{mg} / \mathrm{kg}$ p. $o$. of berberine chloride solution formulation. The dose $(150 \mathrm{mg} / \mathrm{kg})$ of the test item was chosen based on the preliminary experiments performed in the laboratory and observed the quantifiable concentration of this analytic in rat plasma.

\subsection{Formulation Preparation}

Solution formulations of the test item was prepared in $40 \%$ $w / v$ 2-hydroxypropyl- $\beta$-cyclodextrin in distilled water. All formulations were prepared freshly prior to dosing. The dose volume for per oral route was $10 \mathrm{~mL} / \mathrm{kg}$.

\subsection{Pharmacokinetic Studies}

Solution of berberine chloride formulations were freshly prepared for per oral dosing. All rats were fasted overnight and the fasting continued up to 4 hours post dosing with free access to drinking water. The oral test formulation was administered at $150 \mathrm{mg} / \mathrm{kg}$ dose through oral gavage using
$18 \mathrm{G}$ stainless steel intubation cannula. The dosing volume administered was $10 \mathrm{~mL} / \mathrm{kg}$. Blood samples $(\sim 120 \mu \mathrm{L})$ were collected from the jugular vein catheter of three rats from each group at each time point [pre-dose, 0.25, 0.5, 01, 2, 4, 8, 12, 24, 36 and 48 hours (p.o.)]. Samples were collected into labeled micro centrifuge tubes, containing 20\% $w / v$ dipotassium ethylenediamine tetracetic acid $\left(\mathrm{K}_{2}\right.$ EDTA) as an anticoagulant. Plasma samples were separated from the blood by centrifugation at $2500 \mathrm{~g}$ for $10 \mathrm{~min}$ at $4 \pm 2{ }^{\circ} \mathrm{C}$ and stored below $-40^{\circ} \mathrm{C}$ (Thermo Scientific, USA) deep freezer until bioanalysis.

\subsection{LC-MS/MS Analysis}

LC-MS/MS analysis of rat plasma samples was performed using API 4000 Applied Biosystem-Sciex triple quadruple mass analyzer system (Concord, Ontario, Canada) with an Turbo Ion Spray interface connected to a Shimadzu UFLC system (Shimadzu Corp., Japan). The optimum operating parameters were determined by electro spray ionization (ESI) interface in positive ion mode. A generic mass spectrometry parameters of the analyte were developed and used for the analysis. These parameters were the declustering potential range (50), collision energy range (32), collision cell exit potential range (8), curtain gas (30 arbitrary units), collisionally activated dissociation gas (10), Turbo ion spray voltage $(4500 \mathrm{~V})$, source temperature $\left(550^{\circ} \mathrm{C}\right)$, ion source gas i.e. nebulizer gas (60 arb) and turbo ion spray gas (40 arb), curtain gas (30 arb) and collision gas (10 arb). Interface heaters were kept on for the analyte. The analyte was detected by positive ion spray in the multiple reaction monitoring mode (MRM) mode using predetermined parent/product mass transition ion pairs. The parameters of the selected MRM monitoring transitions for the $[\mathrm{M}+\mathrm{H}]^{+}$ precursor ion to selected product ion $(\mathrm{m} / \mathrm{z})$ were optimized with 337.40/323.10 (berberine), and 515.30/276.20 (telmisartan as an internal standard. The whole system was controlled by Analyst ${ }^{\circledR}$ version 1.6.3 software (AppliedBiosystem-Sciex, Concord Canada). Stock solutions of berberine and telmisartan (internal standard, IS) were prepared in methanol at approximately $4.175 \mathrm{mg} / \mathrm{mL}$ and 0.8 $\mathrm{mg} / \mathrm{mL}$, respectively and subsequently diluted which were used for the bioanalysis. The extraction procedure for plasma samples or the spiked into plasma calibration standards were identical. A $50 \mu \mathrm{L}$ sample of either study sample or spiked calibration standard/quality control samples were added to individual wells of 96 well plate with $500 \mu \mathrm{L}$ capacity. 200 $\mu \mathrm{L}$ of internal standard (IS, $490 \mathrm{ng} / \mathrm{mL}$ ) prepared in acetonitrile (ACN) was added to the samples in deep well plate except for blank, where $200 \mu \mathrm{L}$ of ACN was added and vortexed for 5 minutes. Samples were centrifuged for 10 minutes at a speed of $4000 \mathrm{rpm}(3220 \mathrm{~g})$ at $4^{\circ} \mathrm{C}$. Following centrifugation, $120 \mu \mathrm{L}$ of supernatant was transferred into $1000 \mu \mathrm{L}$ capacity deep well plate and mixed with $120 \mu \mathrm{L}$ of methanol: water, 50:50 v/v. The plate was kept in the autosampler for LC-MS/MS analysis. A Shimadzu LC-20AD LC system (Shimadzu Corp., Japan) was connected to a SIL -20 AC HT auto-sampler (Shimadzu Corp., Japan). The 
supernatant were injected $(20 \mu \mathrm{L})$ onto a Phenomenex, Kinetex EVO, C18 HPLC column, 50 x $4.6 \mathrm{~mm}(5 \mu \mathrm{m})$ (Waters, Massachusetts, Ireland). Analytes were eluted using a gradient elution program with a mobile phase consists of $0.1 \%$ formic acid in water (pump A) with methanol (pump B) at a flow rate of $1.0 \mathrm{~mL} / \mathrm{min}$. The column temperature was at $40^{\circ} \mathrm{C}$ and the sample temperature was at $15^{\circ} \mathrm{C}$. The following linear gradient was employed for the separation: $95 \% \mathrm{~A}$ for $0.01 \mathrm{~min}, 5 \% \mathrm{~A}$ at $0.80 \mathrm{~min}$, and hold to $2.80 \mathrm{~min}, 95 \% \mathrm{~A}$ at $2.90 \mathrm{~min}$ and hold to $4.00 \mathrm{~min}$. The berberine and telmisartan elution times were approximately 1.34 and $1.54 \mathrm{~min}$, respectively. Peak integration, regression and calculation of analytes concentration were computed using Analyst Classic (Version 1.5) software. The calibration curve was performed by linear curve fit of the peak area ratio (analyte/internal standard) as a function of the concentration in the respective matrix. A weighting of $1 / x 2$ (where $\mathrm{x}$ is the concentration of a given calibration standard level) was found to be optimal. The limit of quantification (LOQ) in rat plasma was 1.02 $\mathrm{ng} / \mathrm{mL}$ for berberine. Analysis of berberine in plasma (1.02 to $1015.73 \mathrm{ng} / \mathrm{mL}$ ) showed a repeatability (relative standard deviation-RSD \%) of $2.8 \%$ to $10.2 \%$ and accuracy of $99 \%$ to $107 \%$.

\subsection{Pharmacokinetic Analysis}

The pharmacokinetic parameters of berberine were obtained by noncompartmental analysis module in Phoenix WinNonlin $^{\circledR}$ (Version 7.0) (Pharsight, Mountain View, CA).
The areas under the concentration time curve $\left(\mathrm{AUC}_{0-\mathrm{t}}\right.$ and $\mathrm{AUC}_{0-\infty}$ ) were calculated by linear trapezoidal rule. The terminal elimination rate constant $\left(\mathrm{k}_{\mathrm{el}}\right)$ was determined by regression analysis of the linear terminal portion of the $\log$ plasma concentration-time curve. The terminal half-life $\left(\mathrm{T}_{1 / 2}\right)$ was estimated as $0.693 / \mathrm{k}_{\mathrm{el}}$. The apparent oral clearance $(\mathrm{CL} / F)$ were calculated for per oral dose divided by AUC, respectively. Peak berberine concentrations $\left(C_{\max }\right)$ and the times when they occurred $\left(t_{\max }\right)$ were derived directly from the data. The relative oral bioavailability $(\mathrm{Fr})$ was estimated by $\mathrm{AUC}_{\text {treated }} / \mathrm{AUC}_{\text {control}}$.

\subsection{Statistical Analysis}

All mean values are presented with their standard deviation (mean \pm S. D.). Data were analyzed for statistically significant differences using one-way analysis of variance (ANOVA) followed by the two-sided unpaired Student's $t$ test. Differences were considered to be significant at a level of $p<0.05$.

\section{Results and Discussions}

In vivo Effects of Biofield Energy Treatment on Berberine Pharmacokinetics in Rats

The mean pharmacokinetic parameters and profiles of berberine in the rat plasma after a single oral dose of administration of solution formulations in three different groups are summarized in Table 1, and Figure 1, respectively.

Table 1. Pharmacokinetic parameters of berberine after oral administration at $150 \mathrm{mg} / \mathrm{kg}$ body weight to Sprague Dawley male rats.

\begin{tabular}{llll}
\hline Parameter & Gr. 1 (Untreated Berberine) & Gr. 2 (Biofield Treated Berberine) & Gr. 3 (Biofield Treated Rats + Untreated Berberine) \\
\hline $\mathrm{C}_{\max }(\mathrm{ng} / \mathrm{mL})$ & 12.73 & 492.83 & 17.90 \\
$\mathrm{~T}_{\max }(\mathrm{h})$ & 9.33 & 1.58 & 10.67 \\
$\mathrm{AUC}_{0-\mathrm{t}}\left(\mathrm{ng} / \mathrm{mL}^{*} \mathrm{~h}\right)$ & 179.92 & 599.87 & 244.01 \\
$\mathrm{AUC}_{0-\infty}\left(\mathrm{ng} / \mathrm{mL}^{*} \mathrm{~h}\right)$ & 215.90 & 825.19 & 288.23 \\
$\mathrm{~T}_{\text {half }}(\mathrm{h})$ & 18.14 & 18.59 & 10.78 \\
$\mathrm{MRT}_{\text {last }}(\mathrm{h})$ & 14.83 & 7.89 & 13.31 \\
$\mathrm{CL} / \mathrm{F}(\mathrm{L} / \mathrm{h} / \mathrm{kg})$ & 20.53 & 3.88 & 10.20 \\
$\mathrm{Vd} / \mathrm{F}(\mathrm{L} / \mathrm{kg})$ & 3925.72 & 624.07 & 1131.69 \\
$\mathrm{~K}_{\mathrm{el}}\left(\mathrm{h}^{-1}\right)$ & 0.06 & 0.05 & 0.08 \\
$\mathrm{~K}_{\mathrm{a}}\left(\left(\mathrm{h}^{-1}\right)\right)$ & 0.10 & 1.20 & 0.12 \\
$\mathrm{MAT}(\mathrm{h})$ & 9.87 & 2.93 & 8.34 \\
$\%$ Change in Fr & & 233.54 & 35.58 \\
\hline
\end{tabular}

The data are expressed as mean values. AUC, area under the plasma concentration-time curve from 0 hours to infinity; $\mathrm{CL} / F$ : apparent oral plasma clearance; $\mathrm{Vd} / F$ : apparent volume of distribution; $\mathrm{C}_{\max }$, peak concentration; $\mathrm{T}_{\max }$, time to reach peak concentration; $\mathrm{T}_{1 / 2}$, terminal half-life; $\mathrm{K}_{\mathrm{el}}$, absorption rate constant; $\mathrm{K}_{\mathrm{a}}$, absorption rate constant, MRT, mean residence time; MAT, mean absorption time; Fr: relative bioavailability; $p$. o.: per oral, Fr: Relative oral Bioavailability.

The $\mathrm{C}_{\max }$ of berberine formulation in control group was $12.73 \mathrm{ng} / \mathrm{mL}$ after 9.33 hours, whereas it was $492.83 \mathrm{ng} / \mathrm{mL}$ and $17.90 \mathrm{ng} / \mathrm{mL}$ for the berberine formulation after 1.58 hours and 10.67 hours in G2 and G3 groups, respectively. The results showed that berberine had a very low oral exposure $\left(\mathrm{AUC}_{0-\mathrm{t}}\right)$ of $179.92 \mathrm{ng} / \mathrm{mL}$ in control (untreated) group. Biofield Energy Treatment by a renowned Biofield Energy Healer, Alice Branton, the relative oral exposure $\left(\mathrm{AUC}_{0-\mathrm{t}}\right)$ of berberine was significantly enhanced by $233.40 \%(p<0.01)$ and $35.62 \%(p<0.05)$ in $\mathrm{G} 2$ and $\mathrm{G} 3$ groups, respectively as compared to the control group. Experimental data suggest that Biofield Energy Treatment by Alice Branton also significantly improved $(p<0.05)$ the plasma peak concentration $\left(\mathrm{C}_{\max }\right)$ of berberine by 37.7 and 1.4 times, in $\mathrm{G} 2$ and $\mathrm{G} 3$ groups, respectively as compared to the control group. The absorption rate constant $\left(\mathrm{K}_{\mathrm{a}}\right)$ of berberine in Biofield Energy Treatment group was significantly increased by $100 \%(p<0.05)$ and $16 \%$ in $\mathrm{G} 2$ and G3 groups, respectively compared to the control group. The apparent oral plasma clearance $(\mathrm{CL} / F)$ of berberine was decreased significantly $(p<0.01)$ by $81 \%$ and $50 \%$ in $\mathrm{G} 2$ and 
G3 group, respectively compared to the control group. In addition, various other pharmacokinetic parameters were significantly altered such as apparent volume of distribution $\left(\mathrm{V}_{\mathrm{d}} / F\right)$, mean absorption time (MAT), and mean residence time (MRT) of berberine in Biofield Energy Treated groups as compared to the untreated group (Table 1).

The results indicated that the Biofield Energy Treated berberine and animals per se showed a significant increase in the rate and extent of oral absorption of berberine. The enhanced absorption efficiency may be explained as follows: (1) the huge specific surface area of the berberine formulation, (2) the stability of the berberine formulation in the gastrointestinal tract, and (3) promoted berberine transport through transcellular pathway. The significant improvement of relative oral bioavailability of berberine in the Biofield Energy Treatment groups might be translated and applicable into improved pharmacological effects in various disease conditions.

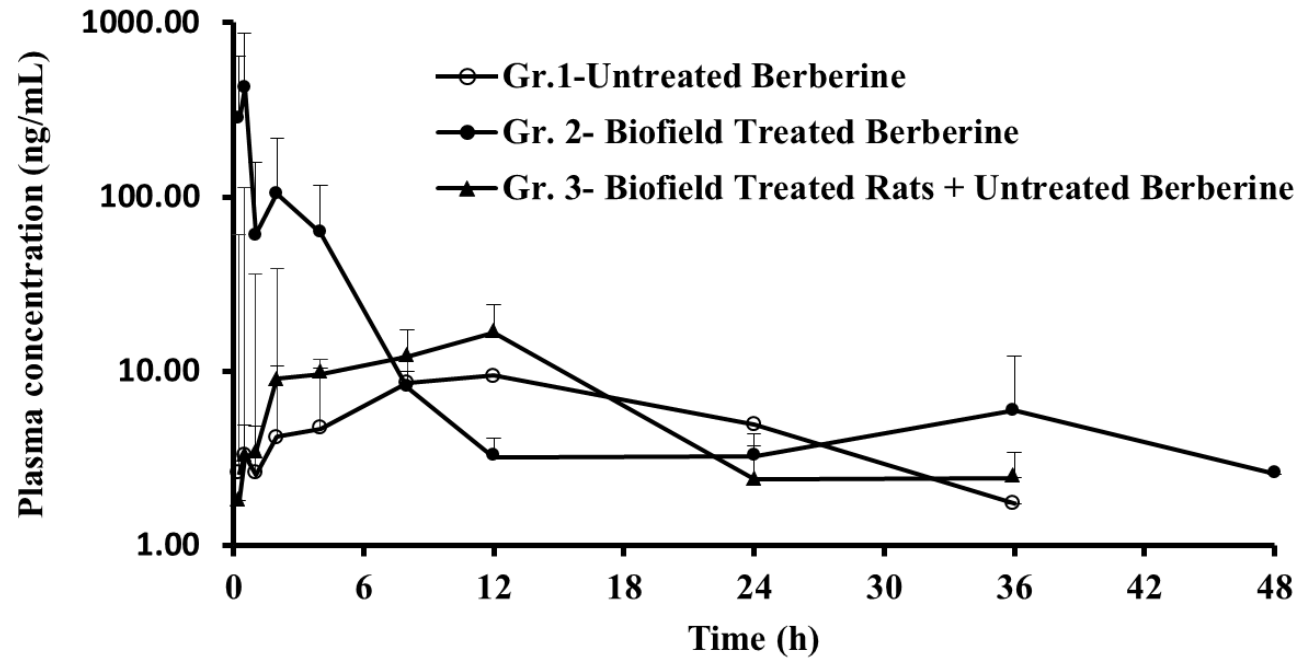

Figure 1. Mean plasma concentration-time profiles of berberine after per oral (p. o.) administration of berberine (150 mg/kg) to Sprague Dawley male rats. The data are expressed as mean $\pm S . D(n=3)$.

Berberine has an extremely low absolute oral bioavailability of $<1 \%$, which is equivalent with the hypothesis that drugs containing the quaternary ammonium groups in their structures commonly have low bioavailability [34]. Further, because of its promising pharmacological activities, various strategies have been tried to improve the oral absorption of berberine [35-37]. Poor bioavailability of berberine is due to many factors, and one important reason is the physicochemical property. It is a hydrophilic compound with a temperature-dependent aqueous solubility which increases with an increase in temperature. It has been reported that berberine has a $\log p$ value of -1.5 and is still considered as poor soluble compound [38], which indicates that it is a biopharmaceutical classification system (BCS) class IV drug. Drugs that belong to BCS class IV such as berberine, which has poor water solubility and lipophobic in nature with poor membrane permeability, and the absorption of the drugs is mostly limited to the paracellular pathway, which limits the intestinal absorption that leads to the low bioavailability [39]. Another important reason is that berberine is a substrate of P-gp, and the bioavailability of berberine is greatly limited due to this ATP-dependent multidrug transporter whereby showed absorbed berberine, which is secreted into the intestinal lumen [40]. An important method used to increase the absorption of drugs being the substrate compounds of P-gp such as berberine is to inhibit the activity of P-gp. This might be one of the reason why several clinical studies based on the oral administration of berberine failed to demonstrate the therapeutic benefits. In the current study, an attempts have been made for the first time successfully to solve the poor oral bioavailability problems associated with berberine by using the novel Biofield Energy Healing Treatment to the test sample/animals. Authors have intentionally chosen this natural product with poor physicochemical properties as model drug in an effort to discern the use of a novel technique in improving the pharmacokinetic effects in vivo. Because of its very poor bioavailability, the dose required for the therapeutic benefit is very high. In vivo bioavailability enhancement is a key determinant for the potential application of a drug/nutraceuticals/food in the clinical setting. Development of the Biofield Energy Treated oral formulation with improved oral pharmacokinetic properties may lead to significant therapeutic benefits in various health conditions. The present results indicated that Biofield Energy Healing could markedly increase the bioavailability of berberine as compared to the untreated berberine. The $\mathrm{C}_{\max }$ and $\mathrm{AUC}_{0-\mathrm{t}}$ of the Biofield Energy Treated berberine preparation were remarkably higher than that of control berberine group. The Biofield Energy Treated formulation of berberine in G2 group and Biofield Energy Treatment per se to the rats (G3 group) resulted in significant increase in the oral absorption of berberine, when compared to the untreated berberine group, G1 (control group). These results clearly demonstrate the significant effect of Biofield Energy Treatment on increased oral absorption of berberine. 


\section{Conclusions}

The limitation of poor permeability of berberine was successfully overcome using Biofield Energy Healing Treatment (The Trivedi Effect ${ }^{\mathbb{B}}$ ) by Alice Branton to the test item and rats. The use of this unique Energy Therapy resulted in significant $(\mathrm{p}<0.05)$ increase $(233 \%)$ in the oral bioavailability and plasma peak concentration $\left(\mathrm{C}_{\max }\right)$ by 37.7 folds of berberine in the Biofield Energy Treated groups, compared to the control group. The absorption rate constant $\left(\mathrm{K}_{\mathrm{a}}\right)$ of berberine in the Biofield Energy Treatment group showed significant increase by $100 \%(p<0.05)$ in G2 group as compared to the control group. The apparent oral plasma clearance $(\mathrm{CL} / F)$ of berberine was significantly $(p<0.01)$ decreased by $81 \%$ and $50 \%$ in G2 and G3 groups, respectively as compared to the control group. It may be due to the significant increase in the aqueous solubility and intestinal permeability that improved oral bioavailability. Therefore, the oral exposure of poorly bioavailable compounds like berberine chloride can be improved using this unique Biofield Energy Healing Treatment. Thereby, the Biofield Energy Treated berberine chloride having improved bioavailability can significantly increase in the antibacterial, anticancer, antidiabetic, anti-obesity, anti-ischemia, memory and cognition, inhibition of metabolic syndrome and neurodegenerative diseases such as Alzheimer's Anxiety and depression. The present findings clearly demonstrate that Biofield Energy Treated test item/formulation prepared through innovative process opens new avenues to overcome the demerits of poorly absorbed drug/nutraceuticals/herbal extracts by improving the therapeutic performance of orally active molecules. All these above results indicated that Biofield Energy Treatment to human per se and the product can be used as a Complementary and Alternative Medicine (CAM) and it has the potential to be an effective and safe for the treatment of different type of health illness.

\section{Acknowledgements}

Authors are grateful to GVK Bioscience, Trivedi Science, Trivedi Global, Inc., Trivedi Testimonials and Trivedi Master Wellness for their support throughout the work.

\section{References}

[1] Inbaraj JJ, Kukielczak B, Bilski P, Sandvik S, Chignell C (2001) Photochemistry and photocytotoxicity of alkaloids from Goldenseal (Hydrastis canadensis L.) Berberine. Chem Res Toxicol 14: 1529-1534.

[2] Tang J, Feng Y, Tsao S, Wang N, Curtain R, Wang Y (2009) Berberine and Coptidis rhizoma as novel antineoplastic agents: a review of traditional use and biomedical investigations. J Ethnopharmacol 126: 5-17.

[3] Singh A, Duggal S, Kaur N, Singh J (2010) Berberine alkaloid with wide spectrum of pharmacological activities. J Nat Prod 3: 64-75.
[4] Chen C, Yu Z, Li Y, Fichna J, Storr M (2014) Effects of Berberine in the gastrointestinal tract $-\mathrm{A}$ review of actions and therapeutic implications. Am J Chin Med 42: 1053-1070.

[5] Stermitz FR, Lorenz P, Tawara JN, Zenewicz LA, Lewis K (2000) Synergy in a medicinal plant: Antimicrobial action of Berberine potentiated by 50 -methoxy hydnocarpin, a multidrug pump inhibitor. Proc Natl Acad Sci USA 97: 1433-1437.

[6] Diogo CV, Machado NG, Barbosa IA, Serafim TL, Burgeiro A, et al. (2011) Berberine as a promising safe anti-cancer agent - is there a role for mitochondria? Curr Drug Targets 12: 850859 .

[7] Brusq JM, Ancellin N, Grondin P, Guillard R, Martin S, Saintillan Y, Issandou M. (2006) Inhibition of lipid synthesis through activation of AMP kinase: an additional mechanism for the hypolipidemic effects of berberine. Journal of Lipid Research 47: 12811288.

[8] Zhou XQ, Zeng XN, Kong H, Sun XL (2008) Neuroprotective effects of berberine on stroke models in vitro and in vivo. Neurosci Lett 447: 3136.

[9] Abd El-Wahab AE, Ghareeb DA, Sarhan EE, Abu-Serie MM, El Demellawy MA (2013) In vitro biological assessment of berberis vulgaris and its active constituent, berberine: antioxidants, anti-acetylcholinesterase, anti-diabetic and anticancer effects. BMC Complement Altern Med 13: 218.

[10] Zeng XH, Zeng XJ, Li YY (2003) Efficacy and safety of berberine for congestive heart failure secondary to ischemic or idiopathic dilated cardiomyopathy. Am J Cardiol 92: 173-176.

[11] Liu YT, Hao HP, Xie HG, Lai L, Wang Q, Liu CX, Wang GJ (2010) Extensive intestinal first-pass elimination and predominant hepatic distribution of berberine explain its low plasma levels in rats. Drug Metab Dispos 38: 1779-1784.

[12] Gupta PK, Hubbard M, Gurley B, Hendrickson HP (2009) Validation of a liquid chromatography-tandem mass spectrometric assay for the quantitative determination of hydrastine and berberine in human serum. J Pharm Biomed Anal 49: 1021-1026.

[13] Chen W, Fan D, Meng L, Miao Y, Yang S, Weng Y, He H, Tang X (2012) Enhancing effects of chitosan and chitosan hydrochloride on intestinal absorption of berberine in rats. Drug Dev Ind Pharm 38: 104-110.

[14] Zhang Y, Cui YL, Gao LN, Jiang HL (2013) Effects of betacyclodextrin on the intestinal absorption of berberine hydrochloride, a P-glycoprotein substrate. Int $\mathrm{J}$ Biol Macromol 59: 363-371.

[15] Maeng HJ, Yoo HJ, Kim IW, Song IS, Chung SJ, Shim CK (20020 P-glycoprotein-mediated transport of berberine across Caco-2 cell monolayers. Journal of Pharmaceutical Sciences 91: 2614-2621.

[16] Movaffaghi Z, Farsi M (2009) Biofield therapies: Biophysical basis and biological regulations. Complement Ther Clin Pract 15: 35-37.

[17] Shenefelt PD (2014) Energy medicine in dermatology. In: Norman RA, Shenefelt PD, Rupani RN, editors. Integrative Dermatology. Oxford University Press, New York, NY, USA.

[18] Trivedi MK, Patil S, Shettigar H, Gangwar M, Jana S (2015) Antimicrobial sensitivity pattern of Pseudomonas fluorescens after biofield treatment. J Infect Dis Ther 3: 222. 
[19] Trivedi MK, Patil S, Shettigar H, Bairwa K, Jana S (2015) Phenotypic and biotypic characterization of Klebsiella oxytoca: An impact of biofield treatment. J Microb Biochem Technol 7: 203-206.

[20] Trivedi MK, Patil S, Shettigar H, Gangwar M, Jana S (2015) An effect of biofield treatment on Multidrug-resistant Burkholderia cepacia: A multihost pathogen. J Trop Dis 3: 167.

[21] Trivedi MK, Branton A, Trivedi D, Nayak G, Shettigar H, Mondal SC, Jana S (2015) Antimicrobial susceptibility pattern, biochemical characteristics and biotyping of Salmonella paratyphi A: An impact of biofield treatment. Clin Microbiol 4: 215.

[22] Trivedi MK, Nayak G, Patil S, Tallapragada RM, Latiyal O (2015) Studies of the atomic and crystalline characteristics of ceramic oxide nano powders after biofield treatment. Ind Eng Manage 4: 161.

[23] Trivedi MK, Patil S, Tallapragada RM (2013) Effect of biofield treatment on the physical and thermal characteristics of silicon, tin and lead powders. J Material Sci Eng 2: 125.

[24] Trivedi MK, Patil S, Tallapragada RM (2013) Effect of biofield treatment on the physical and thermal characteristics of vanadium pentoxide powder. J Material Sci Eng S 11:001.

[25] Trivedi MK, Patil S, Tallapragada RM (2015) Effect of biofield treatment on the physical and thermal characteristics of aluminium powders. Ind Eng Manage 4: 151.

[26] Patil SA, Nayak GB, Barve SS, Tembe RP, Khan RR (2012) Impact of biofield treatment on growth and anatomical characteristics of Pogostemon cablin (Benth.). Biotechnology 11: 154-162.

[27] Altekar N, Nayak G (2015) Effect of biofield treatment on plant growth and adaptation. J Environ Health Sci 1: 1-9.

[28] Shinde V, Sances F, Patil S, Spence A (2012) Impact of biofield treatment on growth and yield of lettuce and tomato. Aust J Basic Appl Sci 6: 100-105.

[29] Sances F, Flora E, Patil S, Spence A, Shinde V (2013) Impact of biofield treatment on ginseng and organic blueberry yield. Agrivita J Agric Sci 35: 22-29.

[30] Lenssen AW (2013) Biofield and fungicide seed treatment influences on soybean productivity, seed quality and weed community. Agricultural Journal 8: 138-143.
[31] Trivedi MK, Mohan TRR (2016) Biofield energy signals, energy transmission and neutrinos. American Journal of Modern Physics 5: 172-176.

[32] Trivedi MK, Branton A, Trivedi D, Nayak G, Balmer AJ, Anagnos D, Kinney JP, Holling JM, Balmer JA, Duprey-Reed LA, Parulkar VR, Panda P, Sethi KK, Jana S (2017) Evaluation of the Energy of Consciousness Healing Treated Withania somnifera (Ashwagandha) root extract using LCMS, GC-MS, and NMR spectroscopy. American Journal of Biomedical and Life Sciences 5 (2), 16-25.

[33] Trivedi MK, Branton A, Trivedi D, Nayak G, Balmer AJ, Anagnos D, Kinney JP, Holling JM, Balmer JA, Duprey-Reed LA, Parulkar VR, Panda P, Sethi KK, Jana S (2017) Evaluation of physicochemical, spectral, thermal and behavioral properties of the Biofield Energy Healing Treated sodium selenate, Science Journal of Chemistry 5 (2), 12-22.

[34] Hua W, Ding L, Chen Y, Gong B, He J, Xu G (2007) Determination of berberine in human plasma by liquid chromatography-electrospray ionization-mass spectrometry. J Pharm Biomed Anal 44: 931-937.

[35] Chen W, Miao Y, Fan DJ, Yang SS, Lin X, Meng LK, Tang X (2011) Bioavailability study of berberine and the enhancing effects of TPGS on intestinal absorption in rats. AAPS Pharm Sci Tech 12: 705-711.

[36] Wang T, Wang N, Song H, Xi X, Wang J, et al. (2011) Preparation of an anhydrous reverse micelle delivery system to enhance oral bioavailability and anti-diabetic efficacy of berberine. Eur J Pharm Sci 44: 127-135.

[37] Fan D, Wu X, Dong W, Sun W, Li J, et al. (2013) Enhancement by sodium caprate and sodium deoxycholate of the gastrointestinal absorption of berberine chloride in rats. Drug Dev Ind Pharm 39: 1447-1456.

[38] Battu SK, Repka MA, Maddineni S, Chittiboyina AG, Avery MA, Majumdar S (2010) Physicochemical characterization of berberine chloride: a perspective in the development of a solution dosage form for oral delivery. AAPS Pharm Sci Tech 11: $1466-475$.

[39] Benet LZ (2010) Predicting drug disposition via application of a Biopharmaceutics drug disposition classification system. Basic Clin Pharmacol Toxicol 106: 162-167.

[40] Pan GY, Wang GJ, Liu XD, Fawcett JP, Xie YY (2002) The involvement of Pglycoprotein in berberine absorption. Pharmacol Toxicol 91: 193-197. 